\title{
Piezoelectric flexible LCP-PZT Composites for Sensor Applications at Elevated Temperatures
}

\author{
J. Tolvanen ${ }^{1}$, J. Hannu ${ }^{1}$, J. Juuti ${ }^{1}$, and H. Jantunen ${ }^{1}$ \\ ${ }^{1}$ Microelectronics Research Unit, University of Oulu, Oulu, 90014, Finland
}

\begin{abstract}
In this paper fabrication of piezoelectric ceramicpolymer composites is demonstrated via filament extrusion enabling cost-efficient large-scale production of highly bendable pressure sensors feasible for elevated temperatures. These composites are fabricated by utilizing environmentally resistant and stable liquid crystal polymer matrix (LCP) with addition of lead zirconate titanate (PZT) at loading levels of 30 vol.\%. These composites, of approximately $0.99 \mathrm{~mm}$ thick and length of $>50 \mathrm{~cm}$, achieved excellent bendability with minimum bending radius of $\sim 6.6 \mathrm{~cm}$. The maximum piezoelectric coefficients $d_{33}$ and $g_{33}$ of the composites were $>14 \mathrm{pC} / \mathrm{N}$ and $>108 \mathrm{mVm} / \mathrm{N}$ at pressure $<10$ $\mathrm{kPa}$. In all cases, the piezoelectric charge coefficient $\left(\mathrm{d}_{33}\right)$ of the composites decreased as a function of pressure. Also, piezoelectric coefficient (d33) further decreased in the case of increased frequency press-release cycle sand pre-stress levels by approximately $37-50 \%$. However, the obtained results provide tools for fabricating novel piezoelectric sensors in highly efficient way for environments with elevated temperatures.
\end{abstract}

Index Terms-Extruder, Flexible, Piezoelectric, Pressure, 3D printing

\section{INTRODUCTION}

Recently various 3D-printable polymer composites with fillers have been intensively studied to improve mechanical properties or add functionality to polymer matrix, [1-2], due to possibilities in smart materials for novel sensors and actuators. Typically, various thermoplastics, e.g. acrylonitrile butadiene styrene (ABS) or polylactic acid (PLA) [1, 3-4], have been used as matrix material due to easy processing. Improvements in mechanical properties or added functionality have been accomplished by utilizing fillers such as barium titanate $\left(\mathrm{BaTiO}_{3}\right)$ and carbon in many forms [5-9], up to $70 \mathrm{wt} . \%$ or 30 vol.\%, respectively. Various additive manufacturing technologies enables fabrication of such materials [10] like fused-deposition modeling (FDM), where long thin filament of molten thermoplastic is extruded through heated nozzle [8]. Even more advanced methods have been proposed, e.g. digital projection printing (DPP) that makes fabrication of high order 3D structures possible [11]. The excellent flexibility of processing, low-costs, and possibility to fabricate high performance products at precisely controlled size and geometry are foremost benefits of 3D printing technology. However, even though these methods are highly applicable to printing of polymers and composites with various structures, they have some drawbacks. One of the most inhibiting factors is the difficulty to fabricate objects that have large volume, surface area or are long in one or multiple dimensions. Such difficulties can be mostly surpassed by using filament extruding, where the length and volume of an object can be adjusted with minor limitations. However, surface area is still more restricted due to size of the processing equipment, as also in 3D-printing techniques. Moreover, as most 3D-printing techniques use filaments for printing, direct filament extruding into desired object eliminates unnecessary processing steps.

One extensively studied application of polymer composites have been piezoelectric materials that can convert mechanical stresses to electrical charge, or vice versa. These have important applications in present and novel sensors, actuators, and various electronics. The most common materials are piezoelectric polymers, such as polyvinylidene fluoride (PVDF) and ceramics as fillers, e.g. lead zirconate titanate (PZT). These materials have one of the best piezoelectric performance among polymers and ceramics having piezoelectric coefficient $\mathrm{d}_{33}$ up to 30 [12] and $300-640 \mathrm{pC} / \mathrm{N}$, respectively $[11,13]$, respectively. Even though feasible piezoelectric materials for various forms of 3D printing is still under development, e.g. different coextruded and metal core structures, and films utilizing PVDF as a matrix material have been developed [1417], these are not suitable in some cases. Also, the matrix materials used in these structures are not proper for high temperatures due to relative low melting and heat deflection temperatures (HDT) of piezoelectric polymers.

In this work fabrication of piezoelectric LCP-PZT composites with PZT loadings levels up to 30 vol. $\%$ is demonstrated via filament extrusion. The main reason why LCP-PZT composites were chosen over other compositions was the development of a composite for elevated sensor applications $\left(\sim 200^{\circ} \mathrm{C}\right)$. When such temperatures are considered, the number of polymer candidates are somewhat limited when costefficient large-scale fabrication possibilities of flexible sensor material has to be still maintained. As the LCP has high melting point and $\mathrm{HDT}$ of $200^{\circ} \mathrm{C}$ at $0.5 \mathrm{MPa}$, it is feasible for the desired temperatures. Also, the LCP is relative cheap type of polymer compared to other possibilities and has extreme environmental stability. To enhance the piezoelectric response multiple possibilities are available, but the PZ26 was chosen due to high Curie temperature and availability. 
The composites were fabricated by two-step process where LCP-PZT composite was first compounded with twin-screw mixing extruder and after granule preparation filament extrusion was carried out to form long and highly bendable strips. The composition, microstructure, mechanical, dielectric, and ferroelectric properties of the composites was investigated by varying poling conditions. The piezoelectric response was further studied by applying low frequency $(<2 \mathrm{~Hz})$ and relative high compressive forces ( $\geq 4 \mathrm{MPa}$ ) to study the functional properties as a sensor.

\section{EXPERIMENTAL PROCEDURE}

\subsection{Materials}

The polymer-ceramic composites were fabricated by using solid LCP granules (LCP A430, Vectra) and PZT powder (PZ26, Ferroperm Piezoceramics A/S). LCP granules have relatively high melting temperature of $280{ }^{\circ} \mathrm{C}$ and density of 1.5 $\mathrm{g} / \mathrm{cm}^{3}$. PZ26 is hard type piezoceramic with density of 7.7 $\mathrm{g} / \mathrm{cm}^{3}$, relative permittivity of 1300 and dielectric loss of 0.003 at $1 \mathrm{kHz}$, piezoelectric coefficient $\mathrm{d}_{33}$ of $330 \mathrm{pC} / \mathrm{N}$, and Curie temperature of $330^{\circ} \mathrm{C}$ [18].

Electrodes were fabricated by screen printing of DuPont 5064H silver conductor (Dupont Taiwan Ltd, Taiwan) and curing the paste at $130{ }^{\circ} \mathrm{C}$ for approximately 10 minutes. The electrode sizes of LCP-PZT-S30 and round reference samples were $35 \mathrm{~mm} \times 0.45 \mathrm{~mm}$ and $200 \mathrm{~mm}^{2}$, respectively.

\subsection{Preparation of LCP-PZT granules}

The composite granules were fabricated with HAAKE Minilab Rheomex CTW5 extruder that has twin-screw with added feedback loop in mixing cavity. The rotation speed in compounding was varied between $30-100 \mathrm{rpm}$ at temperature of $340^{\circ} \mathrm{C}$ where PZT powder was added into melt LCP. Mixing ratio of approximately 4.9 grams to 12.5 grams were used for LCP-PZT 30 vol.\% granules. The compound was mixed for approximately 15 minutes to homogenize the mixture. Afterwards, the melt composite was flushed out through round nozzle as a ribbon with the diameter of approximately $2.5 \mathrm{~mm}$ and then cut into small granules for filament extrusion. Also, granules with PZT loading levels of $37-40$ vol.\% were fabricated.

The LCP-PZT granules were used in filament extruder (Filastruder v2.0) [19] for 3D-printers. The extruder consists of hopper that can be loaded with granules or powder, single auger screw inside coated barrel, connected to $12 \mathrm{~V}$ DC-motor. The motor feeds the granules towards the heated nozzle, feeding the filament through nozzle to belt that speed is matched or slightly increased above the extrusion speed of the extruder (Fig. 1).

The extruder was modified by adding extra heating elements above the nozzle and moving the first heating element further away from the nozzle. This improved the heating capability, increased the temperature at the other end, and restricted temperature fluctuation in the heating zone. The maximum achievable temperature with this setup was approximately $260^{\circ} \mathrm{C}$. Also, the barrel and nozzle were fully insulated to increase the heating area further towards the hopper. The extrusion speed varied as a function of extrusion temperature, rotation speed and amount of material in the auger, and granule size.

\subsection{Preparation of LCP-PZT filaments}

The filament extrusion temperature was varied between 180$290{ }^{\circ} \mathrm{C}$ by gradually increasing or decreasing the temperature to achieve the best quality. The optimal processing temperature for LCP-PZT-filament was found to be approximately $225^{\circ} \mathrm{C}$. With lower temperatures extrusion was not possible. With higher temperature, the porosity of the composite and the speed of extrusion was increased. The pores seemed to open more easily, compared to lower temperatures, when leaving the nozzle. Thus, fabrication of long and straight filaments also became more difficult as the number of pores increase. As a consequence, also the brittleness of the composites increased with increased temperature due to pores.

At temperature of $225^{\circ} \mathrm{C}$, the surface of the filament was rough due to low extruding temperature in comparison to melting temperature of LCP. The low extruding temperature could be explained by prolonged heating period and lengthened heating zone, that softens the granules enough for extrusion. When feeding pressure is finally applied, the softened granules start to melt due to pressure and prolonged heating. Also, as the temperature is measured on the surface of the barrel, the temperature inside the barrel could be somewhat higher. For better surface quality, slight polishing of the filaments was used after fabrication. As an average, thickness of approximately $0.99 \mathrm{~mm}$ was achieved for rectangular filament composites. These LCP-PZT 30 vol.\% filaments, with length of over $50 \mathrm{~cm}$, were highly bendable as the minimum bending radius was approximately $6.6 \mathrm{~cm}$. Steep bending in one direction or shape was possible, however, twisting broke the ribbons more easily.

Composites with $37-40$ vol.\% of PZT, showed that significant increase of loading is not possible with filament extrusion. These composites required higher extrusion temperature of approximately $260{ }^{\circ} \mathrm{C}$, that also decreased the quality of the filament and increased the speed of extrusion as a result. The achieved filaments were extremely porous, brittle, short $(<10 \mathrm{~cm})$ and slightly twisted.

\subsection{Characterization}

The microstructures of cross-sections of LCP-PZT composites were analyzed with Olympus BX51TF optical microscope and Zeiss ULTRA plus FESEM. The mechanical properties including, tensile strength, Young's modulus and strain at break were measured with Linkam TST350 Tensile Stress Testing system with $200 \mathrm{~N}$ force transducer.

The dielectric measurements for composites were obtained at frequencies of $1 \mathrm{kHz}-1 \mathrm{MHz}$ and $1 \mathrm{MHz}-1 \mathrm{GHz}$. For lower frequency measurements, Hewlett Packard 4282A Precision LCR meter was used. The ferroelectric properties of the composites were measured by using Radiant Technologies Precision $10 \mathrm{kV}$ HVI-SC in combination with Precision material analyzer. The dielectric properties of composites at low frequencies were calculated by measuring capacitance of the samples and using parallel-plate equation to calculate the values [20].

The response of the composites to applied pressure was 
recorded by using computer-controlled piston in combination with Agilent Technologies InfiniiVision DSO-X 3024A oscilloscope. The test patterns were fabricated similarly to dielectric and ferroelectric tests. The patterns of $35 \times 4.5 \mathrm{~mm}^{2}$ covered both surfaces (top and bottom) of the samples. The produced pressure was calculated by using Eq. 1

$$
p=F / A
$$

where $\mathrm{F}$ is produced force by the piston, and $\mathrm{A}$ is area of the sample. In addition, the charge generated by the sample during pressure was measured with Keysight B2980 series electrometer to calculate the piezoelectric coefficient by using Eq. 2,

$$
d_{33}=\frac{\sigma_{q}}{\sigma_{33}}
$$

where $\sigma_{\mathrm{q}}$ describes charge density in $\mathrm{C} / \mathrm{m}^{2}$, and $\sigma_{33}$ the produced stress by the piston in $\mathrm{N} / \mathrm{m}^{2}$ (Eq. 2).

\section{RESULTS AND DISCUSSION}

\subsection{Structural properties of the LCP-PZT filaments}

The microstructure of LCP-PZT composites showed high content of voids, that are black dots in Fig.3(c) in the crosssection with average void size of approximately $3.91 \mu \mathrm{m} \pm 2.94$ $\mu \mathrm{m}$ (Fig. 3b). The LCP-PZT composites are homogenous, where medium and small sized void are present in large quantities. Also, this homogenous mix has evenly spread PZT grains of approximately $1-10 \mu \mathrm{m}$ by size. However, there is possibility that large or even extremely large sized void are present (Fig. 3c). These voids are formed when some of the PZT grains come off from the surface of the sample during polishing. In addition, the effects of pressure fluctuation within die during extruding could be seen in one test sample. This varied the density of the composite within cross-section. The large voids ( $\geq 75 \mu \mathrm{m}$ ), pressure fluctuations, and PZT agglomerates should be avoided to further improve the properties of the composite. This requires more precisely controlled filament extruding that also achieves mixing of molded plastic into granules. Also, the number of the voids could be reduced by increasing the recycling of the filament through the extruder or by polishing in more time-consuming manner to further remove the possibility of void formation in the final sample. In addition, typically organic surfactants can be used to improve compounding process to avoid voids, but in this case high temperature processing conditions limited the use of surfactants.

\subsection{Mechanical properties of LCP-PZT filaments}

The mechanical properties of LCP-PZT 30 vol.\% composites were conducted with tensile strength measurement system by measuring multiple individual test samples to obtain value of mean and variance. The results of test samples show unnoticeably small variance within similar composition.

The Young's modulus and tensile strength of pure LCP filaments were approximately $0.168 \mathrm{GPa}$ and $60 \mathrm{MPa}$ at room temperature, respectively. When PZT loading of 30 vol. $\%$ was applied, the Young's modulus stays same and tensile strength decreases to values of $0.163 \mathrm{GPa}$ and $36 \mathrm{MPa}$, respectively (Table 1). Thus, PZT loading does not affect stiffness of the material compared to pure polymer, but its ability to elongate decreases. The stress-strain behavior of the LCP and LCP-PZT 30 vol.\% strips shows linear and similar behavior in Fig.4, but the composite fractures earlier.

\subsection{Dielectric properties of LCP-PZT composites}

The low frequency dielectric properties of LCP-PZT composites are shown in Table 2. The LCP-PZT filaments with 30 vol.\% of PZT show decrease in relative permittivity from 14.71 to 13.53 as frequency increases from $1 \mathrm{kHz}$ to $1 \mathrm{MHz}$. The dielectric losses of the composites rapidly decrease between frequencies of $100 \mathrm{kHz}-1 \mathrm{MHz}$, eventually achieving values of 0.013 at $1 \mathrm{MHz}$. It should be noted that, the high content of voids in the filament decreases the attainable relative permittivies, as seen also in other cases were materials were printed [7].

\subsection{Ferroelectric properties and polarization of LCP-PZT composites}

The ferroelectric properties of LCP-PZT composites were measured by varying voltage between $1-5 \mathrm{kV} / \mathrm{mm}$, when samples were put into silicon path at room temperature and elevated temperature of $100^{\circ} \mathrm{C}$. The maximum polarization electric field for room temperature and $100^{\circ} \mathrm{C}$ were observed to be 4 and $5 \mathrm{kV} / \mathrm{mm}$, respectively. At these electric fields, the polarization shows linear relation with applied electrical field. This is typical behavior of dielectric materials. The saturated hysteresis loop would surely be the optimal but unfortunately this could not be reached due to modest dielectric breakdown of the composite. Furthermore, the polarization is zero when no electrical field is applied i.e. no remanent polarization could be found within measurement accuracy although some hysteresis loop opening could be seen at negative electric fields (Fig. 5).

However, the effects of polarization were studied by observing the change of dielectric properties when individual samples were poled in various poling conditions (P1-P4). The poling of samples was accomplished by applying external electric field of $3.5-5 \mathrm{kV} / \mathrm{mm}$ at temperature of $100^{\circ} \mathrm{C}$, in direction of thickness (Fig. 6), when samples were in silicon path and poling time was varied from 0.5 to 2 hours (Table 3 ). The results show that neither the applied electrical field (3.5-5 $\mathrm{kV} / \mathrm{mm}$ ) nor poling time (0.5-2 hours) affected the outcome when comparing the obtained values at these conditions.

The relative permittivity values show $0.8-1.4 \%$ increase depending on the sample and frequency. Also, dielectric losses of these samples increase approximately $1-2 \%$ for frequency range of $1 \mathrm{kHz}-1 \mathrm{MHz}$. Also, higher temperature of $120^{\circ} \mathrm{C}$ was tested but no further improvements was seen.

\subsection{Pressure sensitivity of LCP-PZT composites}

The response of round reference samples (LCP-PZT-R40, LCPPZT-R50) and LCP-PZT 30 vol.\% strips were studied by applying pressure between $0.2-4.5 \mathrm{MPa}$ with programmable piston. The reference samples were prepared with injection moulding system and had diameter of approximately $1.6 \mathrm{~cm}$ 
with PZT loading of $40 \mathrm{vol} . \%$ (LCP-PZT-R40) and $50 \mathrm{vol} \%$ (LCP-PZT-R50). The performance of the strips, when unpoled (LCP-PZT-S30) and poled at P4-condition (LCP-PZT-S30 (P4)), was compared to fabricated round reference samples with PZT loading level of 40 and $50 \mathrm{vol} \%$. Also, effect of various compression profiles and pre-stress levels to response of LCPPZT-S30 (P4) sample was studied. The size of test samples for LCP-PZT-S30 and round reference samples were approximately $35 \mathrm{~mm}$ x $0.45 \mathrm{~mm}$ and $200 \mathrm{~mm}^{2}$, respectively. The applied force was distributed to surface of the samples fully covered with printed electrodes in all cases.

In all cases, the response to applied pressure show non-linear relationship in the measurement range of the samples (Fig. 7a). The test samples LCP-PZT-R40, LCP-PZT-R50, LCP-PZTS30, and LCP-PZT-S30 (P4) show voltage change of approximately $280,430,300$, and $200 \%$ when pressure increases from minimum to maximum, respectively. The voltage response of unpoled LCP-PZT-S30 could have two possible explanations. Firstly, this could be explained by direct flexoelectric effect, where electric polarization would be generated due to mechanical strain gradient [21]. As the mechanisms of flexoelectricity in polymers or polymer composites are not well understood, there could be multiple reason that could result in polarization in LCP-PZT. The heterogeneously distributed dipole moments under uneven mechanical deformation could result in non-zero net dipole moment [22]. Also, the direct flexoelectric effect of LCP-PZT could be related to molecular rotations [21], where topology of transverse isotropy yields net overall polarization. Secondly, the piezoelectric crystals of LCP-PZT could be somewhat randomly and irregularly orientated, yet result in directional non-zero net polarization.

The maximum values for voltages $19.2,19.2,12$, and $29 \mathrm{mV}$, respectively, without amplification and measured directly with oscilloscope with $1 \mathrm{M} \Omega$ impedance. When PZT loading level increased from 30 to $40-50 \mathrm{vol} \%$, the response to applied pressure increases. This behavior is seen after 0.25 and $0.5 \mathrm{MPa}$ for $50 \mathrm{vol} . \%$ and $40 \mathrm{vol} . \%$, respectively. The increase in responsivity is approximately $0-130 \%$ depending on the pressure. The relationship between PZT loading level and increased response is nonlinear, and cannot be directly calculated. Also, the large difference in responses between round reference samples and strips are closely related to large difference in the PZT loading levels (10-20 vol.\%) rather than shape of the samples. Also, poling of LCP-PZT sensor strip changes the response to applied pressure. As a result of poling condition $\mathrm{P} 4$, the dynamic range of sensor increases approximately by $240 \%$, whereas voltage change to applied pressure stays the same regardless of the higher initial values at low pressure. But then, the higher initial values of P4 increase the applicability of the sensor to measurements at lower pressure range (>0.5 MPa). The measurements start at the point of first noticeable and possible measurement due to combination of used pre-stress levels, difficult adjustment of generated pressure by the piston at low pressure regimes, and extremely small or unnoticeable voltage responses at low pressures. When observing the variation in the responses (lower values at higher pressures), attachment in the testing setup should be considered. At high pressures, samples could slightly shift or rotate during press-release that affects pressure distribution and response when pressing with the piston. Thus, it can be said that higher pressures give higher response, regardless of the minor deviation in some cases.

Also, effect of different compression profiles (F1-F6) and pre-stress variation to measurement results of test sample $\mathrm{P} 4$ were measured (Fig. 7b) which are defined at Table 4. It should be noted, that when the value of starting position increases the movement range decreases, whereas pre-stress also increases. Thus, varied movement range expresses different levels of prestress. This also increases the repeatability and accuracy of the measurements, when the sample is more tightly mounted between the heads. Also, frequency of press-release cycles slightly varies from $1.1 \mathrm{~Hz}$, when the distance to sample decreases but can be considered as constant in this case.

When the compression profile changes from F1 to F6, the minimum and maximum values of voltage decrease, whereas the slope of curve (voltage to pressure) is relative constant regardless of the compression profile. For other compression profiles between F2-F5, the observed changes are relative insignificant, as the pre-stress change between these profiles is relative low when comparing the change of pre-stress between F1 and F6, where F1 has almost no pre-stress and F6 has prestress of approximately $0.36 \mathrm{MPa}$. The higher pre-stress decreases the pressure sensitivity of the test sample by approximately 50-70 \% at low pressure regime of $<0.4 \mathrm{MPa}$. When pressure increases, the differences in the sensitivities decreases to values of approximately $37-50 \%$. This has drastic effect to the performance of LCP-PZT sensor.

In addition, the response of LCP-PZT-S30 (P4) to continuous press-release cycles at force of $3 \mathrm{MPa}$ with frequency of approximately $1 \mathrm{~Hz}$ was recorded (Fig. 8). The test samples show well defined response of approximately 30 and $-10 \mathrm{mV}$, when the piston presses the surface of samples and the piston is released, respectively. No disturbance in the response was observed. However, test samples showed minor disturbances at some of the compression profiles (F1-F2), where the pre-stress level was significantly lower. These disappeared when compression profiles changed. At this point it should be noted, that the testing setup and printed patterns can affect the response when continuous and prolonged testing with high force measurements are used. The impacts can slightly change the position of the sample (especially with low pre-stress level profiles), thus, pressure distribution can vary, and also repeated cycles can wear down the printed electrodes what eventually gives reduced and/or disturbed output. These factors should be taken into account when interpreting the results. The disturbance peaks were taken into account when the sensor responses were measured. As seen, The LCP-PZT-S30 strips show potential for low frequency press-release cycle measurements. Based on the results of compression profiles to behavior of the sensor, it would be expected that when the frequency and rise time increases, the response would increase if the impedance stays the same. In this case, the accumulate charge would discharge longer time. For high frequency $(\geq 100$ $\mathrm{Hz})$ and low pressure $(\leq 0.1 \mathrm{MPa})$ measurements, the response 
of the sensor would likely be highly reduced or even give no output. Further measurements are required to verify the correlations between higher frequencies, lower applied forces, and sensor performance.

Furthermore, even though higher PZT loadings could not be achieved in strips, it could be that slightly higher PZT loadings would likely increase the sensitivity of the composite. Also, optimization of the poling should be considered to further improve the response of a sensor to applied pressure.

\subsection{Piezoelectric coefficients $\left(d_{33}\right)$}

The results of composite test samples (LCP-PZT-S30, LCPPZT-S30 (P4)) show partly nonlinear behavior of sensitivity to applied pressure, where the sensitivity decreases as a function of the applied pressure (Fig. 9). The nonlinearity could be related to stress distribution during testing of samples. The achieved sensitivities were approximately 0.013-0.009 and 0.103-0.029 pC/N for LCP-PZT-S30 and LCP-PZT-S30 (P4) test samples at pressure ranges of approximately $0.67-3.60$ and 0.53-4.47 MPa, respectively. Thus, when the test sample is poled the initial pressure sensitivity increases by approximately $700 \%$, which then decreases by $240 \%$ when the pressure increases from 0.6 to $4 \mathrm{MPa}$.

In addition, the low stress conditions for LCP-PZT-S30 (P4) were studied by applying low frequency (approx. $1.5 \mathrm{~Hz}$ ) pressrelease cycle by press of fingers (Fig. 10a-b). The applied pressure $(<10 \mathrm{kPa})$ generated electric charge of approximately $20 \mathrm{pC}$ that correlates to piezoelectric coefficient $\mathrm{d}_{33}$ of $>14$ $\mathrm{pC} / \mathrm{N}$ depending on the real value of the applied pressure. The achieved piezoelectricity for LCP-PZT-S30 (P4) at low pressures is rather high when compared to pressure regimes above $0.5 \mathrm{MPa}$. However, the result is in line with piezoelectric behavior were piezoelectricity rapidly decreases as pressure increases and eventually saturates at higher pressures. The slope of the curve Fig. 8 would suggest that approximately $10 \mathrm{pC} / \mathrm{N}$ would be achieved at pressure of $5 \mathrm{kPa}$. However, the low pressure conditions require different testing method as the programmable piston must be pre-stressed and it cannot generate such low pressures for these types of samples. Also, the composite was designed for use at higher pressure regimes (> 2MPa), but the LCP-PZT-S30 clearly shows feasibility also for low pressures.

The calculated piezoelectric coefficient $\mathrm{g}_{33}$ for LCP-PZTS30 show values of $>108 \mathrm{mVm} / \mathrm{N}$ and $0.9 \mathrm{mVm} / \mathrm{N}$ at pressures of $<10 \mathrm{kPa}$ and $0.54 \mathrm{MPa}$, respectively. The values were calculated from $\mathrm{d}_{33}$ coefficient and measured relative permittivity at room temperature. Various PZT based composites based on PC, PVDF, and PDMS have achieved piezolectric coefficients $\mathrm{g}_{33}$ of approximately $17-46 \mathrm{mVm} / \mathrm{N}$ [23-25], $38 \mathrm{mVm} / \mathrm{N}$ [26], and $74 \mathrm{mVm} / \mathrm{N}$ [27], respectively. These values were calculated similar way, but by measuring $d_{33}$ coefficients with various $d_{33}$-meters, where oscillatory force with frequency of $110 \mathrm{~Hz}$ and force amplitudes $\leq 0.5 \mathrm{~N}$ can be used. The achieved results for LCP-PZT are well comparable to these other compositions or even higher (at $<10 \mathrm{kPa}$ ), but with future possibility to utilize at high pressures $(<2 \mathrm{MPa})$ and elevated temperatures $\left(\sim 200^{\circ} \mathrm{C}\right)$.
Coaxial filament based piezoelectric sensors with piezoactive polymers, e.g. P(VDF-TrFE) and PVDF, with copper filament with thin layer of conductive materials and conductive inner and outer layers have achieved pressure sensitivity of 30$380 \mathrm{mv}$ to applied pressure of $0-2 \mathrm{kPa}$ and piezoelectric coefficient $\mathrm{d}_{1 \mathrm{r}}$ 2.78-3.59 $\mathrm{pC} / \mathrm{N}$ measured through charge amplifier, respectively [14-15]. Other types of printed structures, such as PVDF-tourmaline [16] have achieved sensitivities of 1.72-2.06 V with impact test of falling object of $1.02 \mathrm{~kg}$ at height of $0.05 \mathrm{~m}$, that equals to $6.7 \mathrm{kPa}$ pressure. PVDF-films achieved piezoelectric coefficient $\mathrm{d}_{31}$ of 1.19 $\mathrm{pm} / \mathrm{V}$ after corona poling [17]. 3D-printed PVDF sensors were fabricated with responsivity of $0.36 \pm 0.13 \mathrm{pC} / \mathrm{N}$ at $50-400 \mathrm{~N}$, when force was varied by changing the drop height of a steel ball [28]. These values are somewhat similar to achieved results but are not directly comparable in most cases e.g. due to differences in testing. Also, as the sensitivity of LCP-PZT increases rapidly to $>14 \mathrm{pC} / \mathrm{N}$ when the pressure decreases to $<10 \mathrm{kPa}$, thus even higher piezoelectric coefficients are achievable at the lower pressures.

In addition, the other type of filaments reported mostly utilize piezo-active PVDF-blends or ABS that have relative low melting temperature of $\leq 180^{\circ} \mathrm{C}$ [14-17, 23]. Thus, making them unsuitable for high temperature sensor applications above $200{ }^{\circ} \mathrm{C}$. The depoling and Curie temperatures of such materials are even lower (roughly $100{ }^{\circ} \mathrm{C}$ ), thus the applicability for sensing at elevated temperatures is even more limited. Also, other dynamic range of sensor is other important property. The other type of filaments was measured only at small stress, where certain pressure sensing applications would require applicability to higher stress and higher dynamic range. The benefit of the fabricated strips are relative high melting and heat deflection temperatures of LCP, that are 280 and $227^{\circ} \mathrm{C}$ at 0.46 $\mathrm{MPa}$, respectively. Also, the addition of PZT increases these even further. When these are combined with achieved sensitivities, the LCP-PZT-S30 strips are highly applicable for sensor applications in elevated temperature environments.

\section{CONCLUSION}

The piezoelectric composites that can be fabricated via various 3D-printing techniques or as long strips are highly important for novel sensor technologies that require scalability of manufacturing and high cost-efficiency. However, these composites often have low melting and heat deflection temperature of matrix material due to piezoelectric and/or readily processable polymers. These materials cannot withstand elevated temperatures of extreme environments and can be rigid. To further advance in the field of novel sensor technologies, LCP-PZT composites via filament extruding can be utilized to fabricate long and highly bendable piezoelectric composite strips.

The LCP and LCP-PZT 30 vol.\% composites showed Young's modulus and tensile strength of $0.168 \mathrm{GPa}, 0.165 \mathrm{GPa}$, $60 \mathrm{MPa}$, and $36.2 \mathrm{MPa}$, respectively. The relative permittivity and dielectric losses of the LCP-PZT 30 vol.\% composites were approximately 13.5 and 0.013 at $1 \mathrm{MHz}$, respectively. The high content of voids in the composites affected the dielectric 
properties. In regards of ferroelectric properties, no remanent polarization could be found within measurement accuracy although some hysteresis loop opening could be seen at negative electric fields. For polarization, slight increase in the dielectric properties was measured.

The results showed flexible and $0.99 \mathrm{~mm}$ thick LCP-PZT composites, with PZT loading of 30 vol.\%, achieving the maximum piezoelectric coefficients $\mathrm{d}_{33}$ of $>14 \mathrm{pC} / \mathrm{N}$ or $\mathrm{g}_{33}$ of $>$ $108 \mathrm{mVm} / \mathrm{N}$ at $<10 \mathrm{kPa}$, eventually decreasing to $0.103 \mathrm{pC} / \mathrm{N}$ or $0.9 \mathrm{mVm} / \mathrm{N}$ at $0.53 \mathrm{MPa}$ when poled at $\mathrm{P} 4$-condition. For this condition, electric field of $5 \mathrm{kV}$ at temperature of $100{ }^{\circ} \mathrm{C}$ for 2 hours was used. In all cases, the sensitivities decreased as a function of pressure. Also by studying various compression profiles and pre-stress levels were observed to have an effect to responsivity of the sensors to applied pressure. The sensitivity decreased when higher frequency and pre-stress levels were used. Based on the findings, it would be expected that when applied force or pre-stress decreases, the response of the sensor would increase, whereas dynamic range of the sensor would nevertheless be sufficient for different applications ranges.

For further work, the higher frequency measurements $(\geq 100$ $\mathrm{Hz})$ and low-pressure measurements $(<0.1 \mathrm{MPa})$ should be studied to verify the correlations between frequency, force, and sensor performance. For large-scale manufacturing, the poling of the composites during fabrication should be considered to increase cost-efficiency. To achieve higher response, optimization of poling, electrode configuration for sensor, and ways to slightly increase the PZT loading should be studied.

\section{ACKNOWLEDGMENT}

Financial support of the Hybrid materials project (2105/31/2013) of Tekes program of the Finnish Metals and Engineering Competence Cluster (FIMECC Ltd) is gratefully acknowledged. Author J.J. acknowledges the funding of the Academy of Finland (project numbers 267573). Author JT was supported by Riitta and Jorma J. Takanen Foundation, Walter Ahlström Foundation, Tauno Tönning Foundation, and Finnish Foundation for Technology Promotion. Also, authors would like to acknowledgment Dr. Maciej Sobocinski for introducing the filament extruding technique and Dr. Mikko Nelo for helping to find possible solutions to fabricate filaments with higher PZT loadings.

\section{REFERENCES}

[1] Xin Wang, Man Jiang, Zuowan Zhou, Jihue Gou and David Hui, 3D printing of polymer matrix composites: A review and prospective, Composites Part B, 110, pp. 442-458, 2017; doi: 10.106/j.compositesb.2016.11.034

[2] Leigh S. J., Bradley R. J., Purssell, C. P., Billson D. R. and Hutchins D. A., A Simple, Low-Cost Conductive Composite Material for 3D Printing of Electronic Sensors, PLOS ONE, vol. 7, no. 11, e49365, 2012;

[3] Isokov D. V., Lei Q., Castles F., Stevens C. J., Grovenor C. R. M. and Grant P. S., 3D printed anisotropic dielectric composite with metamaterial features, Materials and Design, 93, pp. 423-430, 2016; doi: 10.1016/j.matdes.2015.12.176

[4] Carriro J. D., Traeden N. W., Aureli M. and Leang K. K., Fused filament 3D printing of ionic polymer-metal composites (IPMCs), Smart Mater. Struct., 24, 125021, 2015; doi: 10.1088/0964-1726/24/12/125021
[5] Tekinalp H. L., Kunc V., Velez-Garcia G. M., Duty C. E., Love L. J., Naskar A. K., Blue C. A. and Ozcan S., Highly oriented carbon fiberpolymer composites via additive manufacturing, Composites Science and Technology, 105, pp. 144-150, 2014, doi:10.1016/j.compscitech.2014.10.009

[6] Wang Y., Castles F. and Grant P. S., 3D printing of NiZn ferrite/ABS Magnetic Composites for Electromagnetic Devices, Mater. Res. Soc. Symp. Proc., vol. 1788, 2015; doi: 10.1557/opl.2015.661

[7] Castles F., Isakov D., Lui A., Lei Q., Dancer C. E. J., Wang. Y., Januruding J. M., Speller S. C., Grovenor C. R. M. and Grant P. S., Microwave dielectric characterization of 3D-printed $\mathrm{BaTiO}_{3} / \mathrm{ABS}$ polymer composites, Scientific Reports, 6, 22714, 2016; doi: $10.1038 /$ srep22714

[8] Castro J., Rojas E., Ross A., Weller T. and Wang J., High-k and LowLoss Thermoplastic Composites for Fused Deposition Modeling and their Application to 3D-Printed Ku-Band Antennas, Microwave Symposium, IEEE MTT-S International, 2016; doi: 10.1109/MWSYM.2016.7540068

[9] Ferreira A., Ferreira F. and Paiva C., Textile Sensor Applications with Composite Monofilaments or Polymer / Carbon Nanotubes, Advances in Science and Technology, vol. 80, pp. 65-70, 2012; doi: 10.4028/www.scientific.net/AST.80.65

[10] Matsuzaki R., Ueda M., Namiki M., Jeong T-K., Asahara H., Horiguchi K., Nakamura T., Todoroki A. and Hirona Y., Three-dimensional printing of continuous-fiber composites by in-nozzle impregnation, Scientific Reports, 6, 23058, 2016; doi: 10.1038/srep23058

[11] Kanguk Kim, Wei Zhu, Xin Qu, Chase Aaronson, William R. McCall, Shaochen Chen and Donald J. Sirbuly, 3D Optical Printing of Piezoelectric Nanoparticle - Polymer Composite Materials, ACS Nano, vol. 8, no. 10, pp. 9799-9806, 2014; doi: 10.1021/nn503268f

[12] Anjana Jain, Prashanth K. J., Asheesh Kr. Sharma, Arpit Jain, Rashmi P.N., Dielectric and Piezoelectric Properties of PVDF/PZT Composites: A Review, Polymer Engineering and Science, vol. 55, no. 7, pp. 15891616, 2015; doi: 10.1002/pen.24088/

[13] Volkan Kalem, Ibrahim Çam, and Muharrem Timucin, "Dielectric and piezoelectric properties of PZT ceramics doped with strontium and lanthanum", Ceramics International, vol. 37, no. 4, pp. 1265-1275; doi: 10.1016/j.ceramint.2010.12.003

[14] Kechiche M. B., Bauer F., Harzallah O. and Drean J.-Y., Development of piezoelectric coaxial filament sensors $\mathrm{P}(\mathrm{VDF}-\mathrm{TrFE}) /$ copper for textile structure instrumentation, Sensors and Actuators A, 204, pp. 124-130, 2013; doi: 10.1016/j.sna.2013.10.007

[15] Martins R. S., Goncalves R., Azevedo T., Rocha J. G., Nóbrega J. M, Carvalho H. and Lanceros-Mendez S., Piezoelectric Coaxial Filament Produced by Coextrusion of Poly(vinylidene fluoride) and Electrically Conductive Inner and Outer Layers, J. Appl. Polym. Sci., vol. 131, no. 17, 2014; doi: 10.1002/APP.40710

[16] Bayramol D. V., Effects of tourmaline on the voltage response of PVDF filaments, Industria Textila, vol. 68, pp. 47-53, 2017

[17] Porter D., Hoang T., and Berfield T., Effects of in-situ poling and process parameters on fused filament fabrication printed PVDF sheet mechanical and electrical properties, Additive Manufacturing, vol. 13, pp. 81-92, 2017

[18] Ferroperm, High quality components and materials for the electronic industry, piezo.com/files/files/Ferroperm\%20Catalogue.pdf (year)

[19] Elmore T., Instruction and Assembly Manual for Filastruder, http://www.soliforum.com/topic/2036/filastruder-documentation-andcadstl-files/ (year) 
[20] Tolvanen J., Hannu J., Nelo M., Juuti J., and Jantunen H., Dielectric properties of novel polyurethane-PZT-graphite foam composites, Smart Materials and Structures, 25, 095039, 2016; doi:

[21] Sharma N.D., Maranganti R., and Sharma P., On the possibility of piezoelectric nanocomposites without using piezoelectric materials, Journal of Mechanics and Physics of Solids, vol. 55, no. 11, pp. 23282350, 2007; doi: 10.1016/j.jmps.2007.03.016

[22] Baojin Chu and D. R. Salem, Flexoelectricity in several thermoplastic and thermosetting polymers, Applied Physics Letters, 101, 103905, 2012; doi: $10.1063 / 1.4750064$

[23] Jaitanong N., Yimnirun R., Zeng H.R., Li G.R., Yin Q.R., Chaipanich A., Piezoelectric properties of cement based PVDF/PZT composites, Materials Letters, 130, p. 146-149, 2014

[24] Li Z., Gong H., Zhang Y., Fabrication and piezoelectricity of 0-3 cement based composite with nano-PZT powder, Current Applied Physics, 9, p. 588-591, 2009
[25] Chaipanich A., Effect of PZT particle size on dielectric and piezoelectric properties of PZT-cement composites, Current Applied Physics, 7, p. 574577, 2007

[26] Guan X., Zhang Y., Li H., Ou J., PZT/PVDF composites doped with carbon nanotubes, Sens. Actuator A-Phys., 194, p. 228-231, 2013

[27] Babu I., de With G., Highly flexible piezoelectric 0-3 PZT-PDMS composites with high filler content, Compos. Sci. Technol., 91, p.91-97, 2014

[28] Kirkpatrick M., Tarbutton J., Le T., and Lee C., Characterization of 3D printed piezoelectric sensors: Determination of d33 piezoelectric coefficient for 3D printed polyvinylidene fluoride sensors, Sensors, 2016; doi: 10.1109/ICSENS.2016.7808876 


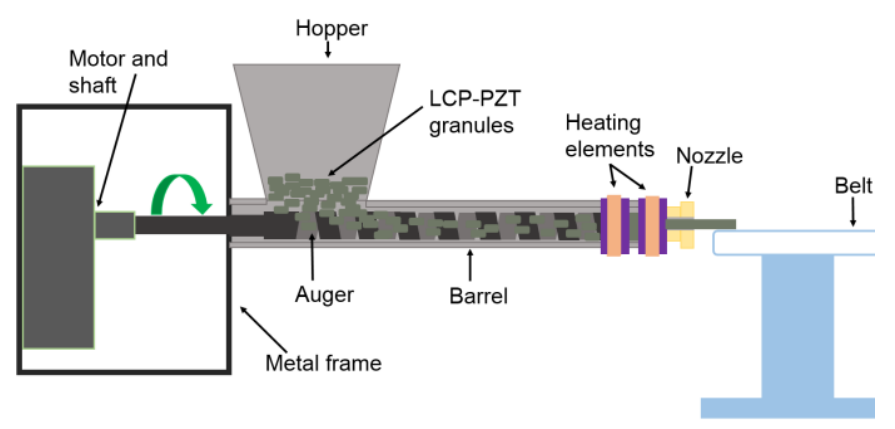

Figure 1. The setup of the modified version of the Filastruder.
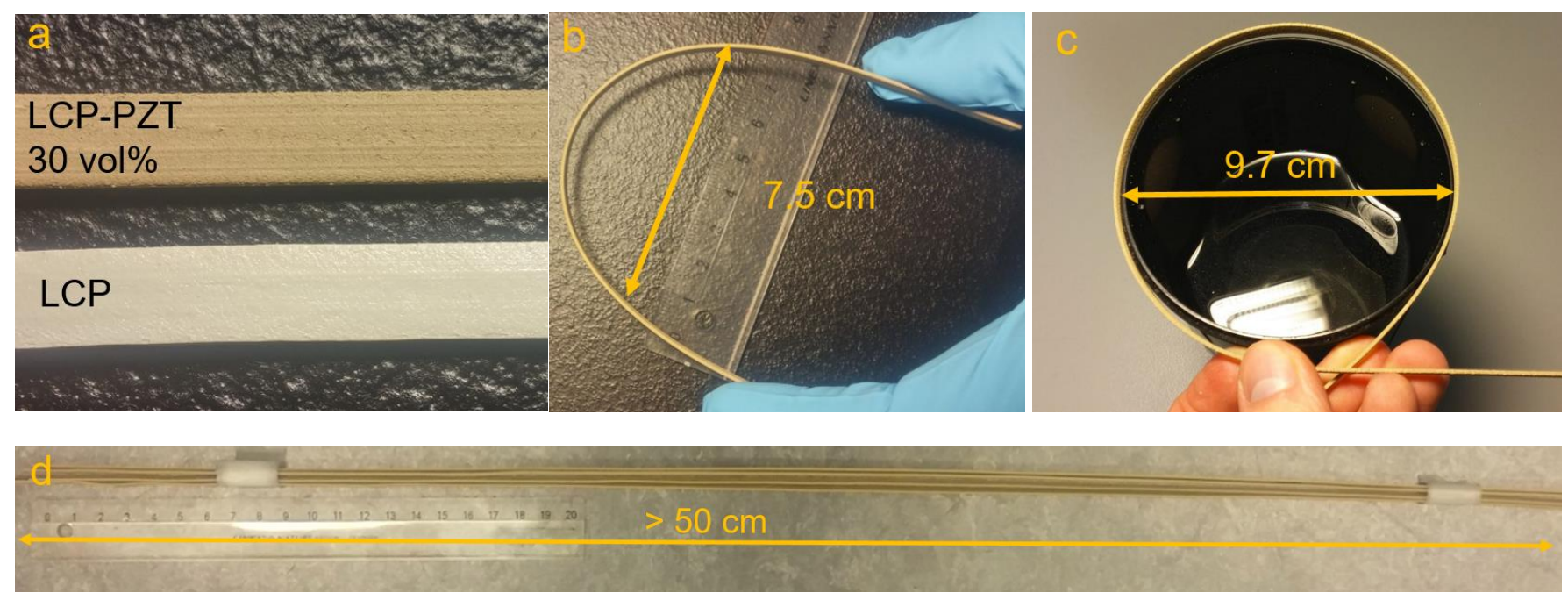

Figures 2a-d. The surfaces of extruded LCP and LCP-PZT 30 vol.\% filaments (a), bending radius of LCP-PZT 30 vol.\% filaments (b-c) with length of $>50 \mathrm{~cm}(\mathrm{~d})$.

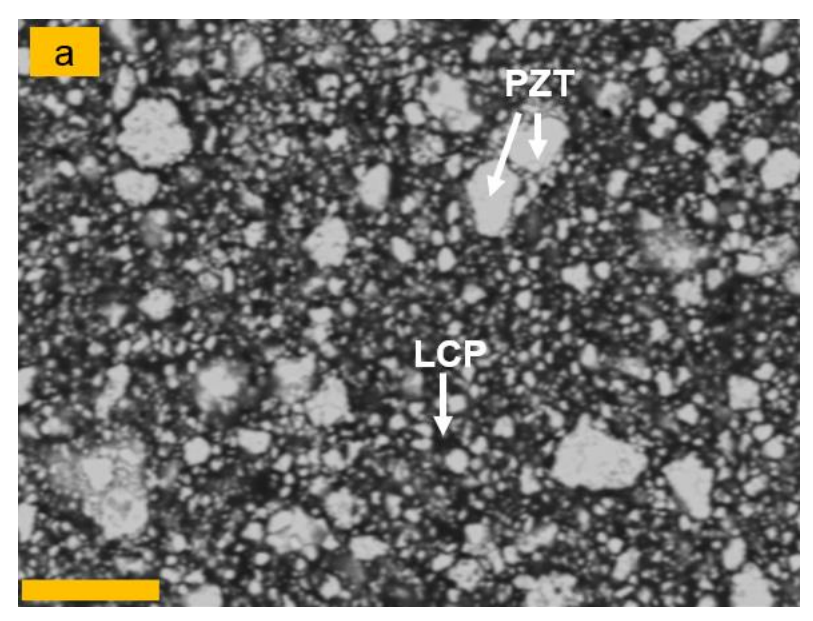



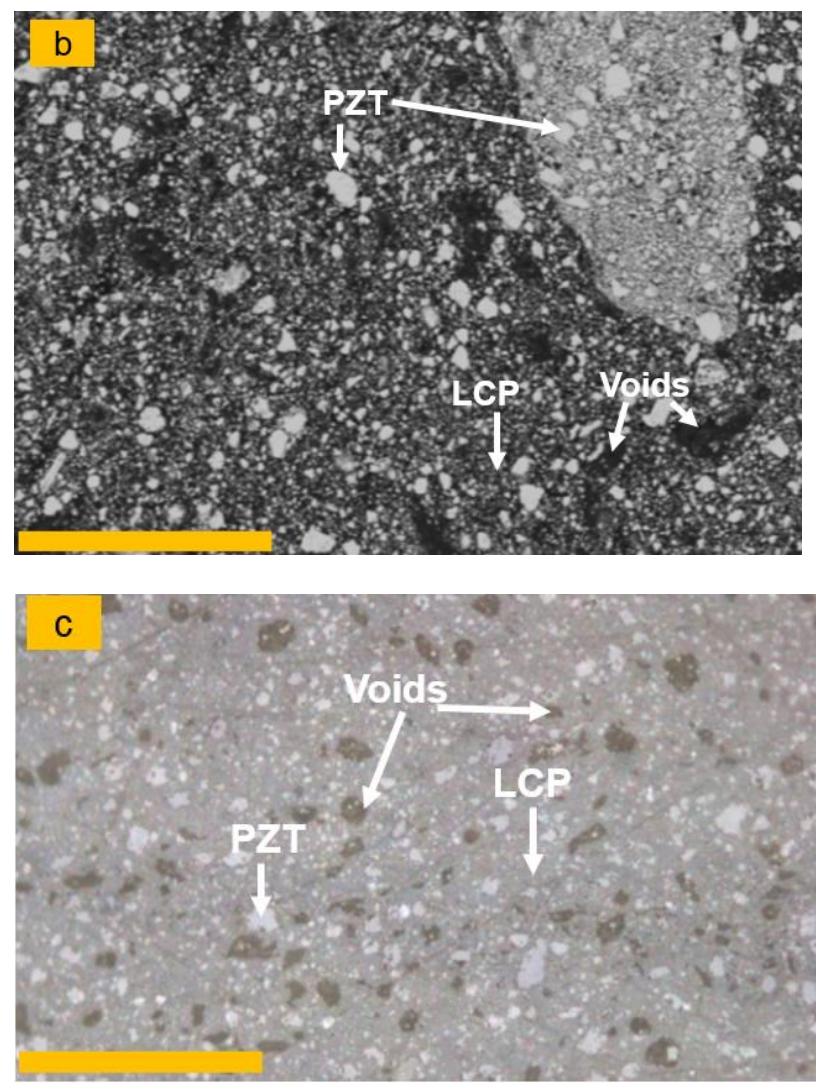

Figures 3a-c. The microstructure of cross-section of LCP-PZT 30 vol.\% composite with FESEM (a) and (b) and optical microscope at magnification of 50 (c). Scale bars $10 \mu \mathrm{m}$ (a),50 $\mu \mathrm{m}$ (b), and $250 \mu \mathrm{m}$.

Table 1. The mechanical properties of LCP and LCP-PZT 30 vol.\% filaments.

\begin{tabular}{ccccccc}
\hline Sample & $\begin{array}{c}\text { Young's modulus } \\
(\mathrm{GPa})\end{array}$ & Strain & $\begin{array}{c}\text { Tensile strength } \\
(\mathrm{MPa})\end{array}$ & $\begin{array}{c}\text { Thickness } \\
(\mathrm{mm})\end{array}$ & $\begin{array}{c}\text { Width } \\
(\mathrm{mm})\end{array}$ & $\begin{array}{c}\text { Length } \\
(\mathrm{mm})\end{array}$ \\
\hline LCP & $0.168 \pm 0.005$ & $0.351 \pm 0$ & $60.0 \pm 2.4$ & $1.03 \pm 0$ & $5.0 \pm 0$ & $35.5 \pm 0.3$ \\
\hline $\begin{array}{c}\text { LCP-PZT } \\
30 \text { vol.\% }\end{array}$ & $0.165 \pm 0.003$ & $0.219 \pm 0$ & $36.2 \pm 1.7$ & $1.02 \pm 0$ & $4.7 \pm 0.1$ & $35.3 \pm 0.4$ \\
\hline
\end{tabular}

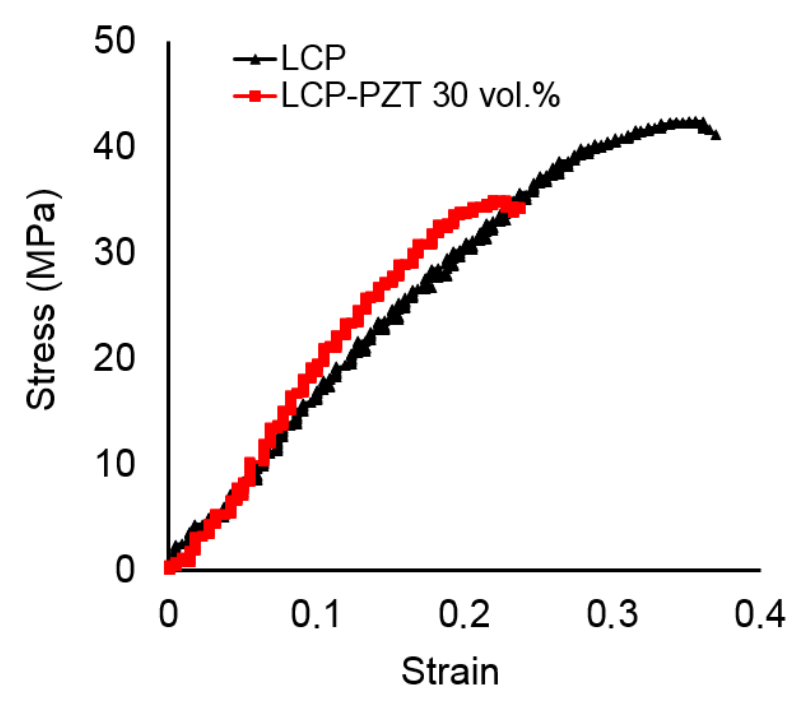

Figure 4. Stress-strain curve of LCP and LCP-PZT 30 vol.\%. 
Table 2. The dielectric properties of LCP-PZT 30 vol.\% filaments at $1 \mathrm{k}-1 \mathrm{MHz}$ frequency.

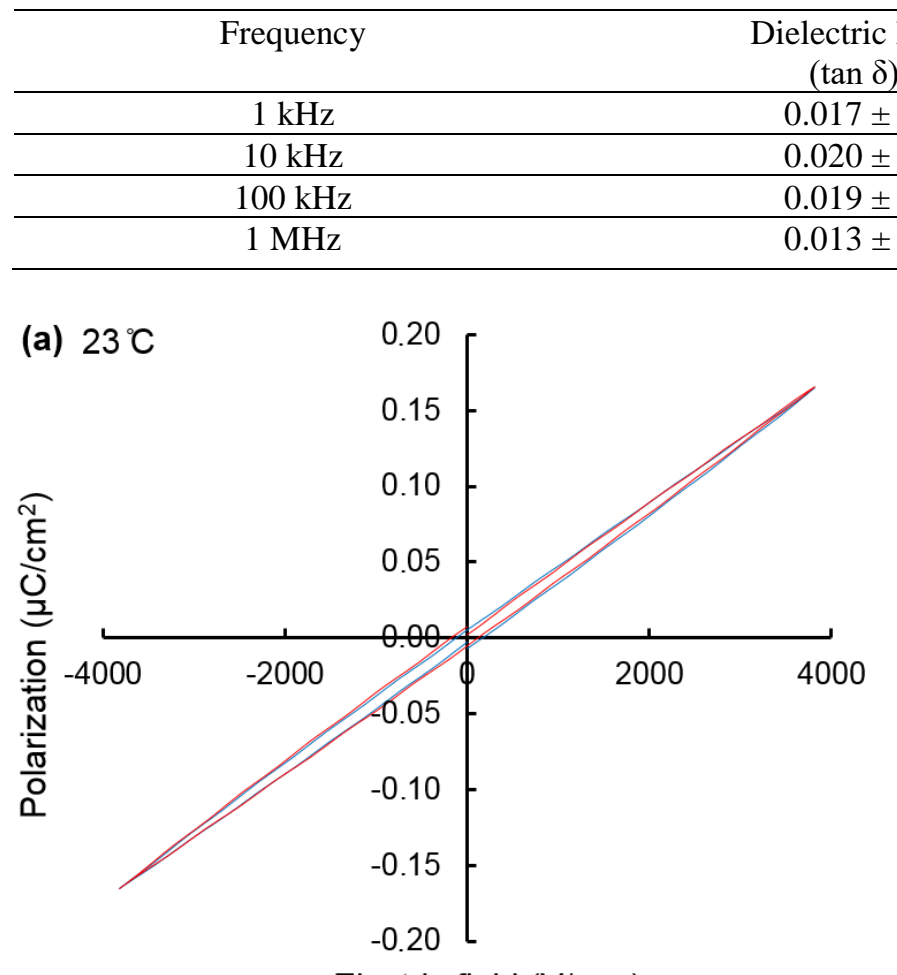

Electric field $(\mathrm{V} / \mathrm{mm})$

Relative permittivity $\left(\varepsilon_{\mathrm{r}}\right)$

$14.7 \pm 0.1$

$13.3 \pm 0.1$

$13.9 \pm 0.1$

$13.5 \pm 0.2$

Figures 5a-b. Ferroelectric hysteresis of LCP-PZT 30 vol.\% filaments at maximum polarization of (a) $4 \mathrm{kV}$ at room temperature and (b) $5 \mathrm{kV} / \mathrm{mm}$ at $100^{\circ} \mathrm{C}$.

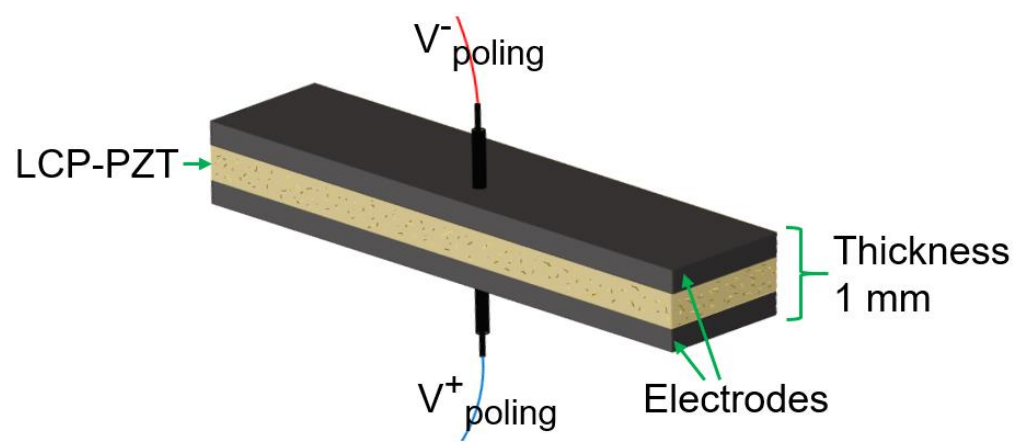

Figure 6. The poling direction and the configuration of electrodes on LCP-PZT's.

Table 3. The dielectric properties of LCP-PZT 30 vol.\% filaments before and after polarization in electric fields of $3.5-5 \mathrm{kV} / \mathrm{mm}$, temperatures of $100{ }^{\circ} \mathrm{C}$, and poling times of $0.5-2$ hours.

\begin{tabular}{cccccc}
\hline $\begin{array}{c}\text { Poling condition } \\
\text { (voltage, temperature, } \\
\text { time) }\end{array}$ & $\begin{array}{c}\text { Frequency } \\
(\mathrm{kHz})\end{array}$ & $\begin{array}{c}\text { Relative } \\
\text { permittivity } \\
\text { before } \\
\left(\varepsilon_{\mathrm{r}}\right)\end{array}$ & $\begin{array}{c}\text { Relative } \\
\text { permittivity } \\
\text { after } \\
\left(\varepsilon_{\mathrm{r}}\right)\end{array}$ & $\begin{array}{c}\text { Dielectric loss } \\
\text { before } \\
(\tan \delta)\end{array}$ & $\begin{array}{c}\text { Dielectric loss } \\
\text { after } \\
(\tan \delta)\end{array}$ \\
\hline $\begin{array}{c}14.5 \mathrm{kV} / \mathrm{mm}, 100^{\circ} \mathrm{C}, 0.5 \mathrm{~h} \\
(\mathrm{P} 1)\end{array}$ & $1-1000$ & 14.43 .2 & $14.5-13.3$ & $0.012-0.013$ & $0.016-0.013$ \\
\hline $\begin{array}{c}5.0 \mathrm{kV} / \mathrm{mm}, 100{ }^{\circ} \mathrm{C}, 0.5 \mathrm{~h} \\
(\mathrm{P} 2)\end{array}$ & $1-1000$ & $14.7-13.5$ & $14.8-13.5$ & $0.019-0.013$ & $0.016-0.013$ \\
\hline $\begin{array}{c}5.0 \mathrm{kV} / \mathrm{mm}, 100^{\circ} \mathrm{C}, 1 \mathrm{~h} \\
(\mathrm{P} 3)\end{array}$ & $1-1000$ & $15.4-14.2$ & $15.6-14.3$ & $0.019-0.013$ & $0.016-0.013$ \\
\hline $5.0 \mathrm{kV} / \mathrm{mm}, 100^{\circ} \mathrm{C}, 2 \mathrm{~h}$ & $1-1000$ & $14.6-13.4$ & $14.8-13.5$ & $0.018-0.013$ & $0.016-0.013$ \\
$(\mathrm{P} 4)$ & & & & & \\
\hline
\end{tabular}



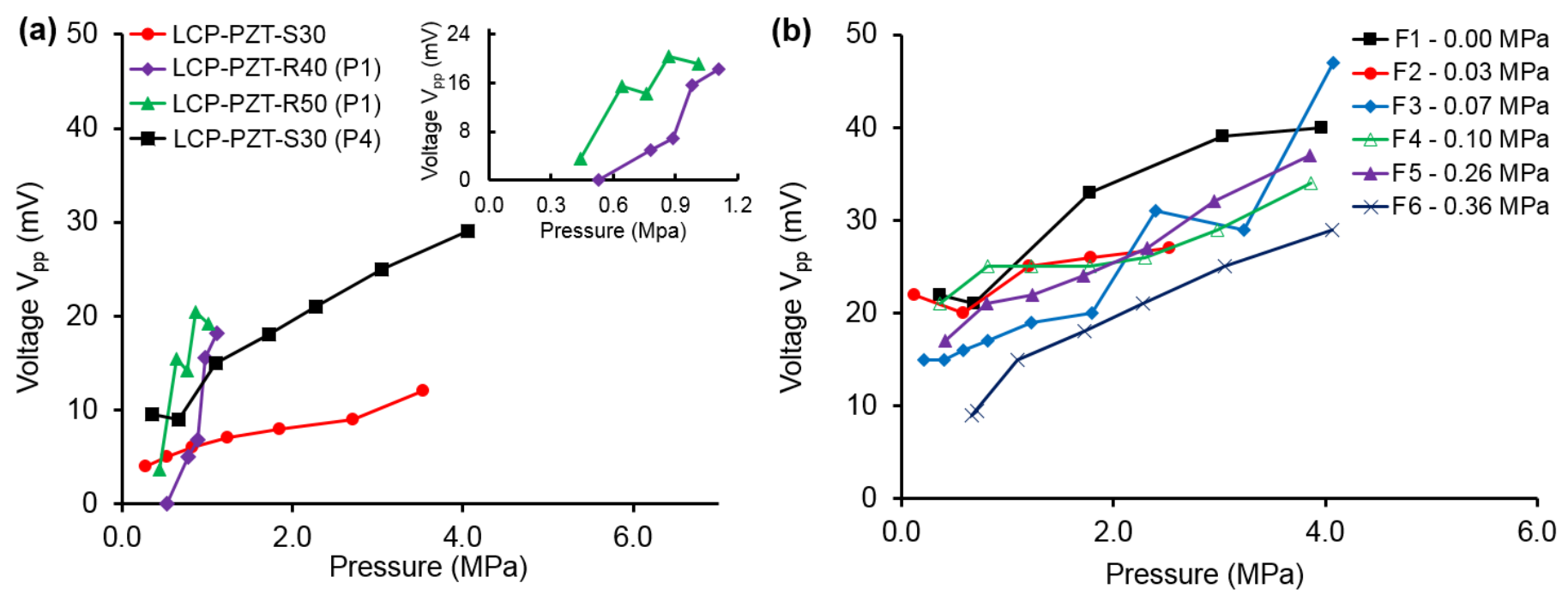

Figure 7 a) The voltage response of round reference samples with PZT loading of 40 and 50 vol.\% (LCP-PZT-R40, LCP-PZTR50), LCP-PZT-S30(30 vol.\%, unpoled), and LCP-PZT-S30(P4) strips to applied pressures, where latter is poled at P4 condition (Table 3). b) The measurements results of LCP-PZT-S30 (P4) sample by using various compression profiles, where pre-stress and movement range are adjusted at constant $1.1 \mathrm{~Hz}$ frequency. (Table 4 ).

Table 4. The compression profile names, pre-stress levels in MPa, and movement ranges for piston in mm, when testing LCP-PZT 30 vol.\% (P4) sample.

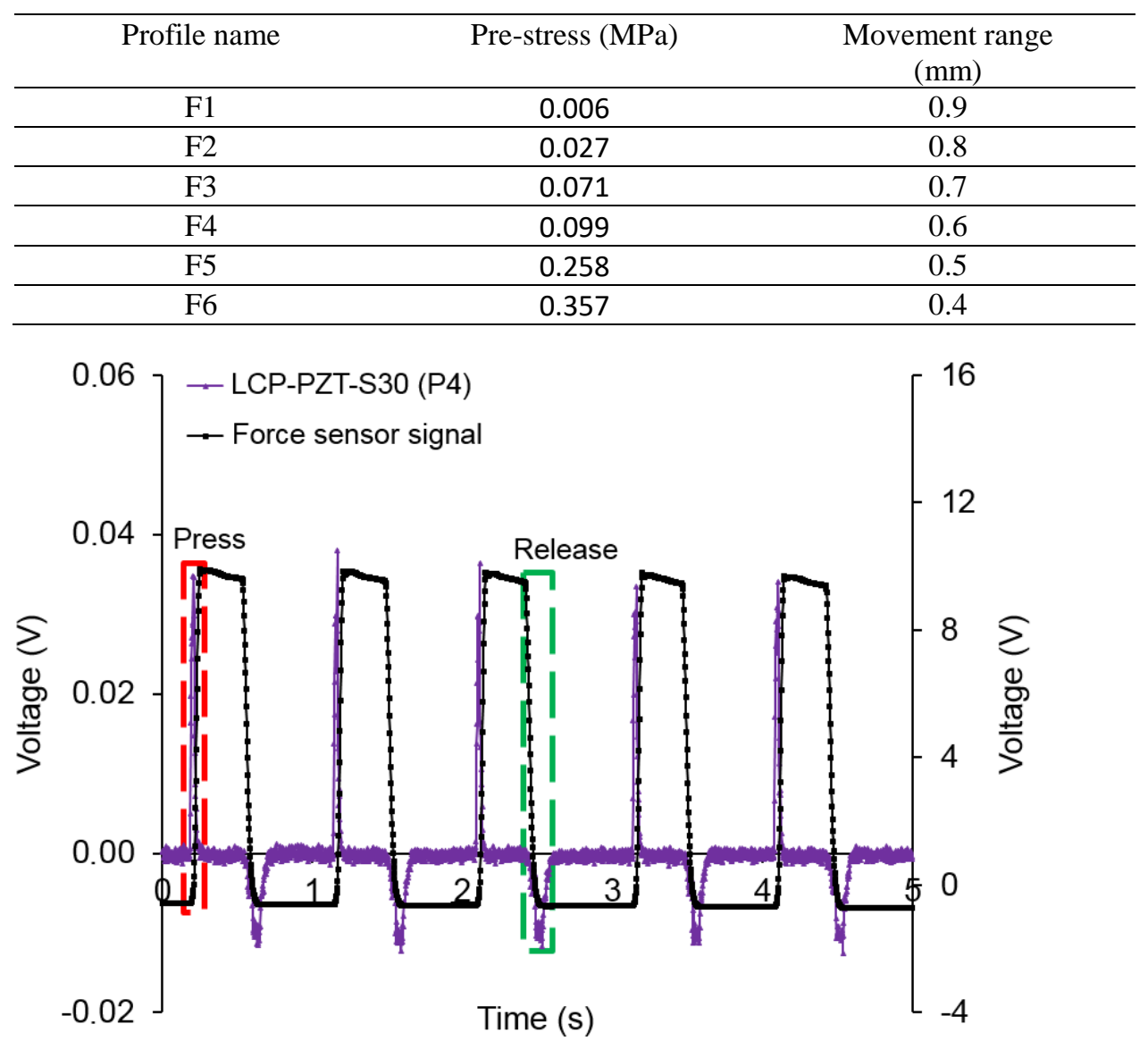

Figure 8. The voltage responses of LCP-PZT-S30 (P4) strip and force sensor to continuously applied press-release cycle at pressure and frequency of approximately $3 \mathrm{MPa}$ and $1 \mathrm{~Hz}$, respectively. 


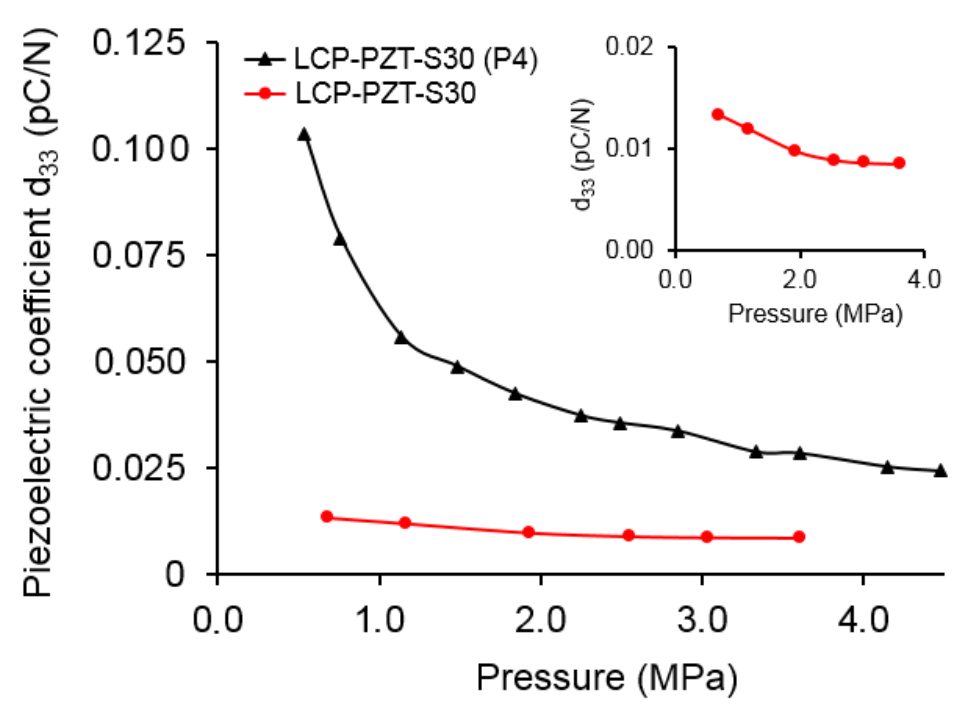

Figure 9. The piezoelectric coefficients of LCP-PZT-S30 strips to applied pressure as a function of pressure, when samples where unpoled and poled at P4 condition.

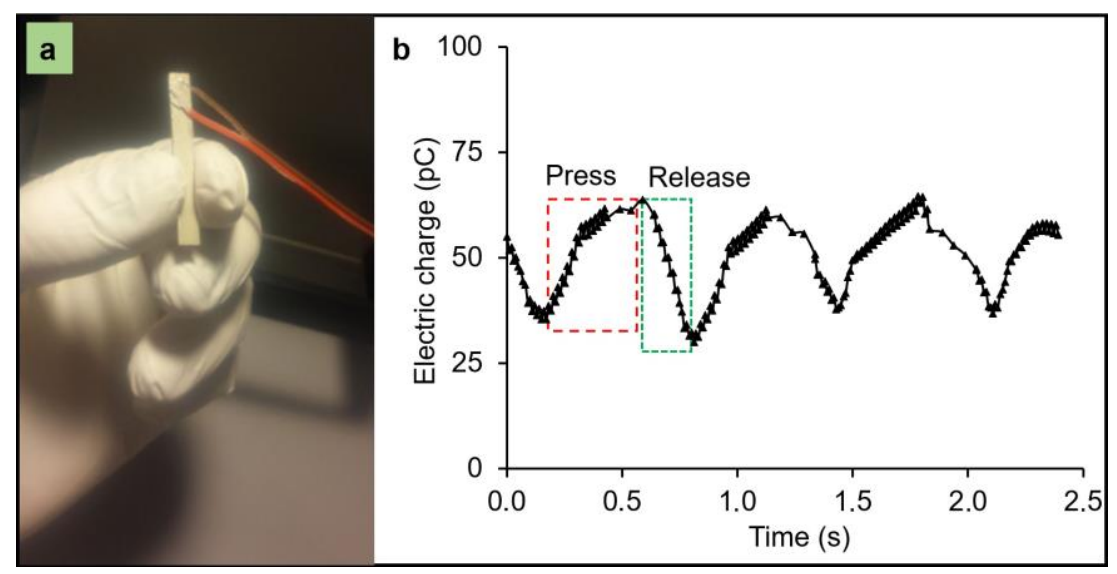

Figure. 10. The LCP-PZT-S30 (P4) sample (a), and the electric charge generated by applied pressure by press of fingers (b). The generated charge correlates to piezoelectric coefficient $\mathrm{d}_{33}$ of approximately $>14 \mathrm{pC} / \mathrm{N}$ at pressure of $<10 \mathrm{kPa}$. 
Table of contents image:

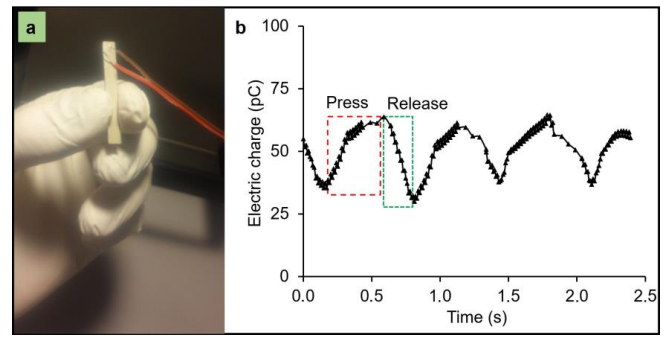

